\title{
Pengaruh Pembelajaran ICT dan Minat Belajar terhadap Kesiapan Membaca Anak Usia Dini
}

\author{
Riskha Hanifa Nasution ${ }^{\varpi_{1}}$, Hapidin $^{2}$, Lara Fridani ${ }^{3}$ \\ Pendidikan Anak Usia Dini, Universitas Negeri Jakarta \\ DOI: $\underline{10.31004 / \text { obsesi.v4i2.411 }}$
}

\begin{abstract}
Abstrak
Penelitian ini bertujuan untuk mengetahui pengaruh pembelajaran ICT dan minat belajar terhadap kesiapan membaca, menggunakan pendekatan kuantitatif dengan metode eksperimen. Populasi penelitian seluruh anak TK B usia 5-6 tahun di Kabupaten Pasaman Barat. Teknik pengambilan sampel menggunakan multistage random sampling. Teknik analisis data menggunakan ANAVA. Hasil penelitian menemukan bahwa 1) Terdapat perbedaan kesiapan membaca anak yang menggunakan pembelajaran ICT berbasis interaktif dan berbasis non interaktif. Hasil perhitungan $\alpha=0,05$ di peroleh $F_{\text {hitung }}$ untuk pembelajaran ICT sebesar 5,849 sedangkan $F_{\text {tabel }} 4,11$. 2) Terdapat perbedaan kesiapan membaca antara anak yang memiliki minat belajar tinggi dan minat belajar rendah. Hasil perhitungan $a=0,05$ diperoleh $F_{\text {hitung }}$ untuk minat belajar sebesar 4,588 sedangkan $F_{\text {tabel }} 4,11$. 3) Pengaruh interaksi pembelajaran ICT dan minat belajar terhadap kesiapan membaca anak. Hasil perhitungan $\mathrm{a}=0,05$ diperoleh $\mathrm{F}_{\text {hitung }}>\mathrm{F}_{\text {tabel }}(74,602>4,11)$. Dampak dari penelitian ini adalah guru lebih memahami cara penggunaan pembelajaran ICT pada anak usia dini.
\end{abstract}

Kata Kunci: pembelajaran ict; minat belajar; kesiapan membaca; anak usia dini

\begin{abstract}
This study aims to determine the effect of ICT learning and learning interest on reading readiness. This research uses a quantitative approach with an experimental method. The population in this study were all kindergarten B children aged 5-6 years in the West Pasaman district. The sampling technique uses multistage random sampling. Data normality test uses liliefors test and data homogeneity test uses levene test. Data analysis techniques used two-way analysis of variance (ANAVA). The results of the study found that 1) There were differences in reading readiness of children who used interactive interactive ICT learning and non interactive interactive ICT learning. The results of two-way ANAVA calculation with $a=0.05$ obtained Fcount for ICT learning amounted to 5.849 while Ftable 4.11. 2) There is a difference in reading readiness between children who have high learning interest and children who have low learning interest. The results of two-way ANAVA calculation $a=0.05$ obtained Fcount for learning interest is 4.588 while Ftable is 4.11 . 3) The influence of ICT learning interactions and learning interests on children's reading readiness. The results of two-way ANAVA calculation for interaction factors $a=0.05$ obtained Fcount of 4.58874 .602 while Ftable of 4.11. The impact of this study is that teachers better understand how to use ICT learning in early childhood.
\end{abstract}

Keywords: ict learning; interest to learn; reading readiness; early childhood

Copyright (c) 2020 Riskha Hanifa Nasution, Hapidin, Lara Fridani

$\square$ Corresponding author:

Email Address : riskhahanifa1@gmail.com (Rawamangun Jakarta, Indonesia)

Received 2 January 2020, Accepted 22 January 2020, Published 28 January 2020 


\section{PENDAHULUAN}

Kemampuan membaca merupakan pemahaman anak terkait dengan simbol, bunyi, kosakata, kalimat dalam bentuk cetak yang diproses dengan kemampuan kognitif yang dimilikinya agar mendapatkan informasi (Niklas, Cohrssen, \& Tayler, 2016). Membaca merupakan proses yang panjang dan rumit yang melibatkan keterampilan kognitif berbeda dan dimulai pada awal perkembangan anak (Sturm, Galal-edeen, \& Shoukry, 2012). Beberapa literatur telah membahas topik tentang anak yang harus bisa membaca telah menjadi masalah universal (Al-barakat \& Bataineh, 2011). Membaca menjadi proses perkembangan yang berkelanjutan dan kesiapan adalah sebuah konsep dalam tahap-tahap membaca tersebut (Majzub \& Kurnia, 2010). Kesiapan membaca sangat penting untuk dikembangkan karena menjadi bagian dari program membaca, seperti anak usia dini mulai mengembangkan pemahaman dasar tentang huruf dan suara sebelum pembelajaran membaca formal dimulai di sekolah. Hal ini menjadi acuan bahwa sebelum anak dapat membaca dengan lancar, terlebih dahulu anak harus melewati proses kesiapan membaca (Sturm et al., 2012).

Hasil riset sebelumnya mengurai tentang pentingnya kesiapan membaca. Kesiapan membaca menunjukkan kematangan perkembangan dan kesiapan seorang anak agar dapat membaca dengan mudah dan mahir. Hal tersebut sangat dibutuhkan anak pada usia 6 tahun, karena masa transisi dari TK menuju sekolah dasar (SD) yang berbeda terkait tuntutan pembelajaran. Kesiapan membaca anak harus dikembangkan oleh karena itu, pendidik harus memahami tingkat kesiapan membaca anak dengan melakukan suatu penilaian (Jannah, 2017). Cabell, Justice, Konold, \& Mcginty, (2011) menjelaskan kesiapan membaca harus disiapkan sejak usia dini agar tidak ketinggalan mengikuti pendidikan di jenjang yang lebih tinggi yang disesuaikan dengan potensi dan tahapan perkembangan anak. Pemenuhan kebutuhan dan kemampuan yang berbeda dari tiap anak memerlukan penyesuaian penggunaan bahan dan metode dalam merealisasikan program kesiapan membaca.

Kenyataannya di Indonesia keterampilan membaca diajarkan pada Pendidikan Anak Usia Dini (PAUD) untuk menjadi syarat tes masuk SD namun belum memperhatikan kesiapan membaca anak. Fridani \& Agbenyega, (2011) mengemukakan bahwa guru taman kanak-kanak memberikan latihan yang cukup intens pada anak dengan harapan dapat membaca dengan lancar menjelang masuk SD. Salah satu alasan guru terkait dengan fakta di lapangan adanya seleksi untuk masuk SD. Alasan ini membuat guru dan orang tua jarang memberikan kesempatan bagi anak untuk mengekspresikan perasaan, minat, dan kreativitas mereka melainkan menggunakan disiplin yang kuat dan mengancam anak untuk memastikan bahwa anak menghafal pelajaran agar lulus ujian masuk sekolah (Fridani \& Agbenyega, 2011). Sehingga perlu untuk melihat kesiapan anak dalam membaca agar kemampuan membaca dapat dicapai secara optimal. Agar dapat menghindari kasus seperti yang terjadi di Garut Jawa Barat, seorang guru yang mengeluarkan delapan orang anak kelas satu karena belum bisa membaca (Heane, 2014).

Menurut Amida (2019), anak yang terkesan dipaksa untuk dapat membaca lancar tanpa melewati kesiapan membaca terlebih dahulu maka pada saat dewasa nanti akan menganggap bahwa membaca menjadi suatu hal yang tidak menyenangkan dan membosankan. Kaitan kesiapan membaca berpengaruh pada konsep kesiapan sekolah yang belum sepenuhnya dipahami oleh para guru dan belum merujuk pada satuan pendidikan di Indonesia untuk menciptakan lingkungan belajar yang positif untuk anak. Guru anak usia dini di Indonesia kebanyakan belum memperhatikan kesiapan membaca anak, oleh karena itu ada beberapa tahapan yang terlewat sehingga ketika dewasa nanti budaya membaca bukanlah menjadi passion pada diri anak, karena anak hanya sekedar membaca saja tetapi tidak tertarik dan tidak berusaha lebih dalam lagi untuk memahami bacaan. 
Teori pembelajaran sosialkultural dari Vygotsky menekankan pentingnya konteks dan pengalaman dalam mewujudkan perkembangan dan mencegah kesulitan membaca di kemudian hari. Konsep utama dari teori ini adalah bagaimana seseorang berinteraksi dengan orang lain dan budaya dapat mempengaruhi kemampuan mentalnya. Dua jenis perkembangan yaitu natural development dan sosiocultural development. Natural development sebagai hasil dari kedewasaan atau kematangan sedangkan sosiocultural development meliputi pengembangan bahasa dan sebagai produk dari kegiatan yang dilakukan seseorang dalam budaya mereka. Vygotsky menjelaskan bahwa cultural tools atau alat-alat budaya tersebut adalah bahasa, tanda-tanda dan simbol. Teori tersebut dapat dikaitkan dengan kesipan membaca anak karena adanya kematangan dan alat-alat budaya sebagai pendukung kesiapan. Kesiapan membaca dipengaruhi oleh lingkungan misalnya seberapa banyak anak bermain dengan buku, bagaimana minat anak pada buku dan dipengaruhi juga oleh kematangan yang tidak dapat dipercepat dengan cara artifisial. Sehingga kesiapan membaca adalah penekanan pada konteks dan pengalaman yang berkaitan dengan pemahaman dalam mentrasfer kata cetak ke dalam bahasa (keterampilan yang berfokus pada kode seperti kesadaran fonologis dan pengetahuan tentang alfabet) dan untuk membangun makna dari teks (keterampilan yang berfokus pada makna seperti kosakata, sintaksis, dan tata bahasa cerita) (Piasta, 2016).

Kesiapan membaca pada anak usia dini juga dipengaruhi oleh beberapa faktor salah satunya adalah minat (Bhadra et al., 2016). Secara khusus, minat dapat dikatakan sebagai motivasi intrinsik. Topik tentang minat dalam kegiatan belajar literasi di taman kanak-kanak relatif masih baru sehingga belum didefinisikan secara luas. Minat diartikan sebagai kegemaran anak dan frekuensi keterlibatan anak dalam kegiatan yang terkait dengan keaksaraan (Baroody \& Oates, 2011). Minat disebut juga sebagai motivasi diri, permainan spontan, ekspolarisi pengalaman sosial dan budaya (Hedges, Cullen, \& Jordan, 2011). Kaitannya dengan belajar bahwa minat menjadi suatu dorongan dari dalam diri anak untuk berpartisipasi aktif yang diterapkan melalui kegiatan belajar sehingga dapat mengubah atau menambah pengetahuan dan pengalaman.

Minat belajar tidak dapat berkembang tanpa adanya interaksi yang berlangsung dengan orang lain dan terlibat dalam suatu kegiatan (Reinhart, Strickler, Czerniak, \& Molitor, 2012). Hal tersebut sesuai dengan teori kontemporer tentang perkembangan minat belajar yang menjelaskan bahwa pentingnya interaksi dan sosialisasi dalam mengembangkan minat (Renninger \& Riley, 2012). Konsep minat berhubungan satu sama lain kerana sama membahas aspek yang saling melengkapi namun berbeda sehingga fokus minat dijadikan menjadi dua yaitu minat individu (anak) dan minat situasional (belajar). Minat individu dikaitkan dengan peningkatan pengetahuan, emosi positif dan nilai. Sedangkan minat belajar dikaitkan dengan efek menarik seperti faktor lingkungan yang ada dalam situasi belajar atau stimulus tertentu yang memicu minat pada situasi belajar. Minat belajar bersifat sementara atau bertahan dalam jangka waktu pendek namun minat belajar menjadi dasar agar dapat menimbulkan minat individu (anak) (Renninger, K. A., Hidi, S., Krapp, 2014).

Menurut Baroody \& Oates, (2011) mengungkapkan keterkaitan kesiapan membaca dengan minat belajar dalam kegiatan literasi memainkan peran penting untuk membangun keterampilan literasi. Anak yang menyukai kegiatan membaca lebih sering berpartisipasi dalam kegiatan daripada anak yang tidak menggemarinya. Kegiatan belajar lebih bermanfaat dan dapat menjadikan anak sebagai pembelajar yang mandiri jika minat sudah diketahui dan dikaitkan dengan kegiatan belajarnya (Shue, 2009). Hal tersebut menjelaskan bahwa diperlukannya pembelajaran yang tepat untuk mengembangkan indikasi tersebut, salah satunya melalui pembelajaran ICT.

Pembelajaran merupakan proses keterlibatan anak dalam kegiatan akademik untuk mendapatkan pengetahuan. Pembelajaran dapat menentukan terwujudnya sikap dan perilaku anak sehingga keterlibatan anak dalam pembelajaran dapat menimbulkan 
kegigihan, perhatian, keinginan, kemandirian dan semangat untuk belajar (Musu, 2015). Kerckaert \& Vanderlinde, 2015) memaparkan ICT dapat mendukung dan meningkatkan pembelajaran atau bahkan mengubah pendidikan secara mendasar tetapi pembelajaran ICT bukan menggantikan pembelajaran yang menggunakan alat lain namun untuk melengkapi agar dapat membantu anak belajar melalui teknologi. Korat menyarankan bahwa ICT yang dirancang dengan baik yang dipilih dengan cermat dapat memberikan pengalaman belajar yang efisien dan menyenangkan untuk perkembangan membaca anak (Korat, 2014). ICT dikategorikan sebagai alat yang harus dimasukkan ke dalam praktek pembelajaran. Namun cara yang dilakukan disesuaikan dengan tahapan perkembangan anak (Chou, Chang, \& Chen, 2017).

Teori dari piaget dan vygotsky yang disebut dengan pendekatan konstruktivisme menegaskan bahwa perkembangan kognitif dan sosial menjadi tujuan dari pendidikan anak usia dini. Teori ini meyakini bahwa pengetahuan tidak diperoleh secara pasif tetapi dengan cara anak yang aktif melakukan eksplorasi maupun eksperimen sehingga dapat membangun pengetahuannya sendiri. Maka pendidik bertindak sebagai fasilitator bagi anak. Konstruktivisme menjadi pendekatan yang berpusat pada anak dalam praktik pendidikan. Hal tersebut sesuai dengan prinsip pembelajaran yaitu anak sebagi pembelajar aktif, sesuai dengan kebutuhan anak, belajar sambil bermain, dan interaksi sosial antara anak. Artinya anak aktif mencari, memecahkan masalah, bekerjasama dalam penggunaan dan pemanfaatan ICT (Chambers, Cheung, \& Slavin, 2016).

Menurut fakta yang tersedia dapat disimpulkan bahwa penelitian tentang kesiapan membaca sudah pernah dilakukan, namun belum ditemukan penelitian yang mengaitkan ketiga variabel (pembelajaran ICT, minat belajar dan kesiapan membaca) secara bersamasama. Mayoritas penelitian pembelajaran ICT meneliti tentang sikap guru dan kompetensi guru dalam mengenalkan teknologi pada anak, dan pemahaman guru tentang minat belajar, bukan melihat pengaruh terhadap kesiapan membaca anak. Minat belajar menjadi peran penting dalam mempengaruhi kesiapan membaca sehingga menumbuhkan keterlibatan anak untuk belajar dan mempraktekkan keterampilan yang dapat membantunya dalam belajar membaca.

Berdasarkan penjelasan di atas maka diperlukan adanya pembelajaran yang dapat meningkatkan minat belajar terhadap kesiapan membaca anak melalui pembelajaran ICT. Peneliti memilih pembelajaran ICT berbasis interaktif dan pembelajaran ICT berbasis non interaktif sehingga dengan pembelajaran ICT diharapkan dapat berpengaruh terhadap kesiapan membaca anak. Selain itu, penelitian ini juga mengkaji subjek penelitian yang memiliki minat belajar tinggi dan minat belajar rendah. Dengan demikian, peneliti tertarik melakukan penelitian dengan judul "Pengaruh pembelajaran ICT dan minat belajar terhadap kesiapan membaca anak TK B".

\section{METODOLOGI}

Metode yang digunakan dalam penelitian ini adalah metode eksperimen. Metode eksperimen dijelaskan seperti mendesain suatu produk, karena setiap produk harus mencapai tujuan begitu juga dengan eksperimen (percobaan). Tujuan harus ditentukan sejak awal untuk mengoptimalkan proses dengan memberikan perlakuan (treatment) sehingga dapat beroperasi dengan baik (Anderson \& Whitcomb, 2010). Tujuan dari penelitian eksperimen adalah untuk menentukan adanya hubungan sebab akibat antara beberapa variabel, hal ini dikarenakan percobaan yang melibatkan kontrol dan pengamatan serta pengukuran yang cermat (Ary, D., Jacobs, L. C., Irvine, C. K. S., \& Walker, 2018).

Desain yang akan digunakan adalah rancangan desain treatment by level $2 \times 2$. Desain penelitian ini terbagi menjadi tiga variabel dengan variabel bebas dalam bentuk variabel perlakuan menggunakan pembelajaran ICT berbasis interaktif dan pembelajaran ICT berbasis non interaktif. Minat belajar sebagai variabel moderator yang terdiri dari minat belajar tinggi dan minat belajar rendah. Variabel terikatnya adalah kesiapan membaca. 
Dalam penelitian ini, teknik pengambilan sampel dilakukan dengan teknik multistage random sampling (Elfil \& Negida, 2017). Secara sederhana rancangan penelitian ini digambarkan sebagai berikut:

Tabel 1 Desain Penelitian Treatment by Level 2x2

\begin{tabular}{|l|l|l|}
\hline \multicolumn{1}{|c|}{ Jenis perlakuan } & \multicolumn{1}{|c|}{$\begin{array}{c}\text { Pembelajaran ICT } \\
\text { berbasis interaktif (A1) }\end{array}$} & $\begin{array}{c}\text { Pembelajaran ICT } \\
\text { berbasis non interaktif } \\
\text { (A2) }\end{array}$ \\
\hline Tinggi (B1) & A1B1 & A2B1 \\
\hline Rendah (B2) & A1B2 & A2B2 \\
\hline
\end{tabular}

Sampel dalam penelitian ini adalah TK Negeri Pembina dan TK Nustim yang berjumlah 40 anak. Teknik analisis data menggunakan analisis deskriptif dan analisis inferensial. Analisis deskriptif digunakan untuk menganalisis data dengan cara mendeskripsikan atau menggambarkan data yang diperoleh tanpa bermaksud membuat kesimpulan yang berlaku umum atau generalisasi (Sudaryono, 2018). Data dari hasil penelitian diolah menggunakan perhitungan dengan bantuan komputer program MS-Excel 2010 dan SPSS versi 16. Hasil dari pengolahan data dapat diketahui nilai rata-rata, median, modus, standart deviasi, range, nilai maksimum, nilai minimum dan koefisien varians yang dibuat dalam tabel frekuensi dan grafik.

Selanjutnya uji normalitas untuk menentukan data sampel berasal dari populasi yang terdistribusi normal. Uji normalitas menggunakan teknik uji liliefors. Dengan kriteria hasil pengujian menunjukkan bahwa Lhitung $<\mathrm{L}_{\text {tabel, }}$, maka data berasal dari populasi terdistribusi normal (Supardi, 2016). Pengujian hipotesis menggunakan taraf signifikansi a= 0,05. Sedangkan uji homogenitas yang bertujuan untuk mengetahui sampel yang terdistribusi normal berasal dari populasi yang variansnya homogen. Uji homogenitas menggunakan uji levene. dengan krietia pengujian jika nilai signifikansi ( $\mathrm{p}$-value) $>0.05$ menunjukkan kelompok data berasal dari populasi yang memiliki varians yang sama (homogen).

Pada analisis inferensial, hipotesis diuji dengan teknik analisis varian (ANAVA) dua jalur 2x2 untuk menguji efek utama A dan efek utama B serta pengaruh interaksi antar A dan B (main effect dan interaction effect) (Supardi, 2016).

\section{HASIL DAN PEMBAHASAN}

\section{Kesiapan Membaca Anak yang menggunakan Pembelajaran ICT}

Kesiapan membaca adalah kesanggupan seseorang yang melibatkan kemampuan fisik dan mental untuk mencapai kematangan dalam menerjemahkan simbol-simbol kedalam bunyi yang bermakna, untuk mendapatkan pengalaman, dan pengetahuan yang berkaitan dengan pengembangan kemampuan membaca. Kesiapan membaca dapat diukur selama berada di prasekolah, ditandai dengan beberapa komponen seperti diskriminasi visual, pengetahuan huruf alfabet, kesadaran fonologis,. Tiga komponen penting yang harus dipahami dalam kesipan membaca anak yaitu: (1) kesiapan membaca tidak harus dilihat sebagai kumpulan kemampuan tunggal yang akan sama untuk semua anak. Artinya sesuatu yang membuat seorang anak siap mungkin dapat berbeda dengan apa yang membuat anak lain siap; (2) apakah seorang anak siap atau tidak tergantung pada kemampuan khususnya, tetapi juga pada instruksi membaca yang akan ditawarkan, berarti kesiapan membaca hanya dapat dinilai ketika seorang anak diberi berbagai kesempatan untuk belajar membaca; (3) kesempatan belajar membaca yang diberikan pada anak akan memperlihatkan informasi tentang kesiapan anak. Pada era millenial ini anak tumbuh dan berkembang dengan internet, ponsel dan bentuk-bentuk lain dari ICT atau interaksi digital sehingga perlu melibatkan ICT kedalam kegiatan pembelajaran anak. Pembelajaran ICT yang digunakan adalah pembelajaran ICT berbasis interaktif dan pembelajaran ICT berbasis non interaktif. Adapun data yang dari kedua pembelajaran adalah: (1) Kesiapan Membaca Anak yang menggunakan Pembelajaran ICT Berbasis Interaktif (A1). Data hasil penelitian yang 
diperoleh dari jawaban responden sebanyak 20 orang anak, skor kesiapan membaca anak yang menggunakan pembelajaran ICT berbasis interaktif secara keseluruhan memiliki skor antara 30 sampai dengan 44 sehingga rentang skor sebesar 14 . Hasil perhitungan data diperoleh rata-rata sebesar 37,7; simpangan baku sebesar 4,58; varians sebesar 20,96; median sebesar 37,5 dan modus sebesar 32. (2) Kesiapan Membaca Anak yang menggunakan Pembelajaran ICT Berbasis Non Interaktif $\left(\mathrm{A}_{2}\right)$. Data hasil penelitian yang diperoleh dari jawaban responden sebanyak 20 orang anak, skor kesiapan membaca anak yang menggunakan pembelajaran ICT berbasis non interaktif memiliki skor antara 30 sampai dengan 43 sehingga rentang skor sebesar 13 . Hasil perhitungan data diperoleh rata-rata sebesar 35,95; simpangan baku sebesar 3,28; varians sebesar 10,79; median sebesar 36 dan modus sebesar 36 .

\section{Kesiapan Membaca Berdasarkan Minat Belajar}

Memberikan kesempatan dan kegiatan yang bervariasi melalui berbagai pengalaman maupun objek tertentu dapat meningkatkan kesiapan membaca anak. Faktor yang mendukung kesiapan membaca anak yaitu, perhatian, motivasi, perkembangan anak, kesehatan anak dan pengalaman anak. Anak sendiri yang menentukan kemauan atau ketertarikan dan kemampuan untuk belajar membaca, karena kemauan dan kemampuan tersebut merupakan kesiapan membaca anak. Hal ini terkait dengan anak yang dapat belajar membaca ketika sesuai dengan kemampuan dan minat belajar. Maka minat belajar adalah suatu kecenderungan yang relatif menetap pada seseorang untuk menunjukkan ketertarikan, kesungguhan, keaktifan dalam mengikuti proses belajar, yang dipengaruhi oleh interaksi antara anak dengan keluarga, teman, masyarakat, dan hasil ekspolarasi lingkungan. Dalam penelitian ini terdapat minat belajar tinggi dan minat belajar rendah dengan deskripsi data sebagai berikut: (1) Kesiapan Membaca Anak yang memiliki Minat Belajar Tinggi (B1). Data hasil penelitian yang diperoleh dari jawaban responden sebanyak 20 orang anak, skor kesiapan membaca anak yang memiliki minat belajar tinggi secara keseluruhan memiliki skor antara 30 sampai dengan 44 sehingga rentang skor sebesar 14 . Hasil perhitungan data diperoleh rata-rata sebesar 37,6; simpangan baku sebesar 4,59; varians sebesar 21,09; median sebesar 37,5 dan modus sebesar 32. (2) Kesiapan Membaca Anak yang Memiliki Minat Belajar Rendah (B2). Data hasil penelitian yang diperoleh dari jawaban responden sebanyak 20 orang anak, skor kesiapan membaca anak yang memiliki minat belajar rendah memiliki skor antara 30 sampai dengan 43 sehingga rentang skor sebesar 13. Hasil perhitungan data diperoleh rata-rata sebesar 36,05; simpangan baku sebesar 3,32; varians sebesar 11; median sebesar 36 dan modus sebesar 37.

\section{Pengaruh Interaksi Pembelajaran ICT dan Minat Belajar terhadap Kesiapan Membaca Anak}

Berbagai cakupan dalam kesiapan membaca seperti diskriminasi visual, kesadaran fonologi dan pengenalan kosakata yang diperlukan untuk melihat kesiapan membaca anak. Kesiapan membaca akan terwujud jika melibatkan minat belajar anak. Definisi minat belajar adalah keterlibatan anak dalam interaksi dengan orang-orang dan benda-benda yang memberikan kesempatan anak untuk melatih kemampuan yang dimiliki, mengeksplorasi lingkungan, dan belajar untuk menguasai kemampuan baru (Dunst, Raab, \& Hamby, 2016). Selanjutnya minat adalah hubungan antara individu dan objek, topik atau peristiwa yang bermakna bagi seorang individu yang dapat menimbulkan rasa ingin tahu dan senang sehingga dapat mempengaruhi cara anak menilai dan terlibat dalam kegiatan serta konsekuensi yang didapat oleh anak (Neitzel, Alexander, \& Johnson, 2019).

Salah satu cara yang dapat digunakan untuk mengembangkan kesiapan membaca melalui minat belajar adalah dengan menggunakan pembelajaran ICT. Menurut penelitian yang berfokus pada penggunaan pembelajaran ICT dalam Pendidikan Anak Usia Dini menunjukkan bahwa ICT saling terkait dengan prinsip pembelajaran yaitu adanya keterlibatan anak untuk dapat aktif dalam pembelajaran, dapat memotivasi dan 
meningkatkan keingintahuan anak karena sesuai dengan perkembangan dan kebutuhannya, lingkungan belajar yang menyenangkan dan lebih berpusat pada anak menimbulkan perhatian anak, ketekunan anak dapat merangsang kreativitasnya (Palaiologou, 2017; Qian \& Clark, 2016; Moore-russo et al., 2015; Yelland, 2011).

Menurut perspektif sosiokultural oleh Vygotsky, ICT dapat mengirimkan pengetahuan kepada anak tentang banyak hal melalui berbagai pengalaman ICT interaktif dan dapat membantu anak belajar menggunakan sistem ICT. Belajar dapat terjadi melalui scaffolding yaitu interaksi anak-anak dengan ICT melalui bimbingan dari orang dewasa atau melalui fitur dari aplikasi tersebut (Kucirkova, Sheehy, \& Messer, 2015). Hal ini menjadikan ICT memiliki potensi yang dapat memberikan anak peluang belajar untuk mengembangkan kesiapan membaca (Crescenzi, Jewitt, \& Price, 2014). Berdasarkan pemaparan tersebut, diduga terdapat pengaruh interaksi antara pembelajaran ICT dan minat belajar anak terhadap kesiapan membaca anak. (1) Kesiapan Membaca Anak yang menggunakan Pembelajaran ICT Berbasis Interaktif yang Memiliki Minat Belajar Tinggi (A1B1). Data skor kesiapan membaca anak yang menggunakan pembelajaran ICT berbasis interaktif dengan minat belajar tinggi yaitu sebanyak 10 orang anak, dengan skor antara 38 sampai dengan 44 sehingga rentang skor sebesar 6 . Hasil perhitungan data diperoleh rata-rata sebesar 41,6; simpangan baku sebesar 2,07; varians sebesar 4,27; median sebesar 42 dan modus sebesar 44 . Distribusi frekuensinya disajikan pada tabel berikut :

Tabel 2 Distribusi Frekuensi Skor Kesiapan Membaca Anak yang menggunakan Pembelajaran ICT Berbasis Interaktif dengan Minat Belajar Tinggi (A1B1)

\begin{tabular}{clllccccc}
\hline \multirow{2}{*}{ No } & \multicolumn{2}{l}{ Kelas Interval } & \multicolumn{2}{c}{ Batas } & & Frekuensi \\
& \multicolumn{2}{l}{ Bawah } & Atas & Absolut & Komulatif & Relatif \\
\hline 1 & 38 & - & 39 & 37,5 & 39,5 & 2 & 2 & $20,00 \%$ \\
2 & 40 & - & 41 & 39,5 & 41,5 & 2 & 4 & $20,00 \%$ \\
3 & 42 & - & 43 & 41,5 & 43,5 & 4 & 8 & $40,00 \%$ \\
4 & 44 & - & 45 & 43,5 & 45,5 & 2 & 10 & $20,00 \%$ \\
\hline
\end{tabular}

(2) Kesiapan Membaca Anak yang menggunakan Pembelajaran ICT Berbasis Non Interaktif yang Memiliki Minat Belajar Tinggi (A2B1)

Data skor kesiapan membaca anak yang menggunakan pembelajaran ICT berbasis non interaktif dengan minat belajar tinggi yaitu sebanyak 10 orang Anak dengan skor antara 30 sampai dengan 37 sehingga rentang skor sebesar 7 . Hasil perhitungan data diperoleh ratarata sebesar 33,6; simpangan baku sebesar 2,17; varians sebesar 4,71; median sebesar 33,5 dan modus sebesar 32. Distribusi frekuensinya disajikan pada tabel berikut :

Tabel 3 Distribusi Frekuensi Skor Kesiapan Membaca Anak yang menggunakan Pembelajaran ICT Berbasis Non Interaktif dengan Minat Belajar Tinggi (A2B1)

\begin{tabular}{|c|c|c|c|c|c|c|c|c|}
\hline \multirow{2}{*}{ No } & \multirow{2}{*}{\multicolumn{3}{|c|}{ Kelas Interval }} & \multicolumn{2}{|c|}{ Batas } & \multicolumn{3}{|c|}{ Frekuensi } \\
\hline & & & & Bawah & Atas & Absolut & Komulatif & Relatif \\
\hline 1 & 30 & - & 31 & 29,5 & 31,5 & 1 & 1 & $10,00 \%$ \\
\hline 2 & 32 & - & 33 & 31,5 & 33,5 & 4 & 5 & $40,00 \%$ \\
\hline 3 & 34 & - & 35 & 33,5 & 35,5 & 3 & 8 & $30,00 \%$ \\
\hline \multirow[t]{2}{*}{4} & 36 & - & 37 & 35,5 & 37,5 & 2 & 10 & $20,00 \%$ \\
\hline & & & & & & 10 & & $100,00 \%$ \\
\hline
\end{tabular}

(3) Kesiapan Membaca Anak yang menggunakan Pembelajaran ICT Berbasis Interaktif yang Memiliki Minat Belajar Rendah (A1B2).

Data Skor Kesiapan Membaca Anak yang menggunakan Pembelajaran ICT Berbasis Interaktif dengan Minat Belajar Rendah yaitu sebanyak 10 orang dengan skor antara 30 
sampai dengan 37 sehingga rentang skor sebesar 7 . Hasil perhitungan data diperoleh ratarata sebesar 33,8; simpangan baku sebesar 2,49; varians sebesar 6,18; median sebesar 34 dan modus sebesar 37 .

Tabel 4 Distribusi Frekuensi Skor Kesiapan Membaca Anak yang menggunakan Pembelajaran ICT Berbasis Interaktif dengan Minat Belajar Rendah (A1B2)

\begin{tabular}{|c|c|c|c|c|c|c|c|}
\hline \multirow{2}{*}{ No } & \multirow{2}{*}{\multicolumn{2}{|c|}{ Kelas Interval }} & \multicolumn{2}{|c|}{ Batas } & \multicolumn{3}{|c|}{ Frekuensi } \\
\hline & & & Bawah & Atas & Absolut & Komulatif & Relatif \\
\hline 1 & 30 & 31 & 29,5 & 31,5 & 2 & 2 & $20,00 \%$ \\
\hline 2 & 32 & 33 & 31,5 & 33,5 & 2 & 4 & $20,00 \%$ \\
\hline 3 & 34 & 35 & 33,5 & 35,5 & 3 & 7 & $30,00 \%$ \\
\hline \multirow[t]{2}{*}{4} & 36 & 37 & 35,5 & 37,5 & 3 & 10 & $30,00 \%$ \\
\hline & & & & & 10 & & $100,00 \%$ \\
\hline
\end{tabular}

(4) Kesiapan Membaca Anak yang menggunakan Pembelajaran ICT Berbasis Non Interaktif yang Memiliki Minat Belajar Rendah (A2B2)

Data Skor Kesiapan Membaca Anak yang menggunakan pembelajaran ICT berbasis non interaktif dengan minat belajar rendah yaitu sebanyak 10 orang Anak dengan skor antara 36 sampai dengan 43 sehingga rentang skor sebesar 7 . Hasil perhitungan data diperoleh rata-rata sebesar 38,3; simpangan baku sebesar 2,41; varians sebesar 5,79; median sebesar 37,5 dan modus sebesar 36. Distribusi frekuensinya disajikan pada tabel berikut :

Tabel 5 Distribusi Frekuensi Skor Kesiapan Membaca pada anak yang menggunakan Pembelajaran ICT Berbasis Non Interaktif yang Memiliki Minat Belajar Rendah (A2B2)

\begin{tabular}{clllccccc}
\hline \multirow{2}{*}{ No } & \multicolumn{2}{l}{ Kelas Interval } & \multicolumn{2}{c}{ Batas } & Baw & Absolut & $\begin{array}{c}\text { Frekuensi } \\
\text { Komulatif }\end{array}$ & Relatif \\
\hline 1 & 36 & - & 37 & 35,5 & 37,5 & 5 & 5 & $50,00 \%$ \\
2 & 38 & - & 39 & 37,5 & 39,5 & 2 & 7 & $20,00 \%$ \\
3 & 40 & - & 41 & 39,5 & 41,5 & 2 & 9 & $20,00 \%$ \\
4 & 42 & - & 43 & 41,5 & 43,5 & 1 & 10 & $10,00 \%$ \\
\hline
\end{tabular}

Hasil pengujian normalitas dan homogenitas data menunjukkan bahwa kelompokkelompok data dalam penelitian berasal dari populasi yang berdistribusi normal dan memiliki varians yang homogen. Maka selanjutnya dapat menggunakan analisis varians (ANAVA) dalam pengujia hipotesis penelitian.

(1) Pengaruh utama (Main Effect) untuk melihat dan menguji pengaruh X1 terhadap $Y$ (pembelajaran ICT terhadap kesiapan membaca). Pembelajaran ICT yang digunakan dalam penelitian ini adalah pembelajaran ICT berbasis interaktif $\left(\mathrm{A}_{1}\right)$ dan pembelajaran ICT berbasis non interaktif $\left(\mathrm{A}_{2}\right)$, untuk mengetahui signifikan atau tidaknya perbedaan yang ada dilakukan dengan uji F, dengan kriteria pengujian Fhitung > Ftabel, maka dapat disimpulkan perbedaan kesiapan membaca antara kelompok A1 dan kelompok A2 adalah signifikan. Adapun pengujian hipotesis dilakukan sebagai berikut:

$\mathrm{H}_{0}$ diterima jika $\mu_{\mathrm{A} 1} \leq \mu_{\mathrm{A} 2}$

H1 diterima jika $\mu_{\mathrm{A} 1}>\mu_{\mathrm{A} 2}$

$(a=0,05, N=20)$

Keterangan :

$\mathrm{H}_{0}$ : Tidak terdapat perbedaan kesiapan membaca anak antara anak yang menggunakan pembelajaran ICT berbasis interaktif dan pembelajaran ICT berbasis non interaktif. 
$\mathrm{H}_{1}$ : Terdapat perbedaan kesiapan membaca anak antara anak yang menggunakan pembelajaran ICT berbasis interaktif dan pembelajaran ICT berbasis non interaktif

$\mu_{\mathrm{A1}}$ : Rata-rata kesiapan membaca dengan kelompok anak yang menggunakan pembelajaran ICT berbasis interaktif

$\mu_{\text {A2 } 2}$ : Rata-rata kesiapan membaca dengan kelompok anak yang menggunakan pembelajaran ICT berbasis non interaktif

Rata-rata skor kesiapan membaca anak yang menggunakan pembelajaran ICT berbasis interaktif $\left(A_{1}\right)$ adalah 37,7 sedangkan rata-rata skor kesiapan membaca anak yang menggunakan pembelajaran ICT berbasis non interaktif $\left(\mathrm{A}_{2}\right)$ adalah 35,95 . Hasil perhitungan ANAVA dua jalur diperoleh $F_{\text {hitung }}$ untuk pembelajaran ICT sebesar 5,849 sedangkan $F_{\text {tabel }}=$ 4,11 pada taraf nyata $a=0,05$ dan nilai sig $<0,05$ yaitu $(0,021<0,05)$. Perhitungan menyatakan bahwa $\mu$ A1 $>\mu$ A2 $\left(37,7>35,95\right.$ dan $F_{\text {hitung }}>F_{\text {tabel }}(5,849>4,11)$ maka $\left(\mathrm{H}_{0}\right)$ ditolak dan $\mathrm{H}_{1}$ diterima artinya terdapat perbedaan yang signifikan antara kesiapan membaca anak yang menggunakan pembelajaran ICT berbasis interaktif $\left(\mathrm{A}_{1}\right)$ dengan anak yang menggunakan pembelajaran ICT berbasis non interaktif $\left(\mathrm{A}_{2}\right)$. Maka terdapat pengaruh XI (pembelajaran ICT ) terhadap Y (kesiapan membaca).

(2) Pengaruh utama (Main Effect) untuk melihat dan menguji pengaruh X2 terhadap $Y$ (minat belajar terhadap kesiapan membaca). Minat belajar yang dibedakan menjadi minat belajar tinggi $\left(B_{1}\right)$ dan minat belajar rendah $\left(B_{2}\right)$, untuk mengetahui signifikan atau tidaknya perbedaan yang ada dilakukan dengan uji $\mathrm{F}$, dengan kriteria pengujian Fhitung $>\mathrm{F}$ Tabel, maka dapat disimpulkan perbedaan kesiapan membaca antara kelompok B1 dan kelompok B2 adalah signifikan. Hipotesis statistik dirumuskan sebagai berikut :

$\mathrm{H}_{0}: \mu \mathrm{B}_{1} \leq \mu \mathrm{B}_{2}$

$\mathrm{H}_{1}: \mu \mathrm{B}_{1}>\mu \mathrm{B}_{2}$

$(\alpha=0,05, N=20)$

Keterangan :

$\mathrm{H}_{0} \quad$ : Tidak terdapat perbedaan kesiapan membaca anak antara anak yang memiliki minat belajar tinggi dan anak yang memiliki minat belajar rendah.

$\mathrm{H}_{1} \quad$ : Terdapat perbedaan kesiapan membaca anak antara anak yang memiliki minat belajar tinggi dan anak yang memiliki minat belajar rendah

$\mu_{\mathrm{B} 1} \quad$ : $\quad$ Rata-rata skor kesiapan membaca anak yang memiliki minat belajar tinggi

$\mu_{\mathrm{B} 2} \quad$ : Rata-rata skor kesiapan membaca anak yang memiliki minat belajar rendah

Rata-rata skor kesiapan membaca anak yang memiliki minat belajar tinggi $\left(\mathrm{B}_{1}\right)$ adalah 37,60 sedangkan rata-rata skor kesiapan membaca anak yang memiliki minat belajar rendah $\left(\mathrm{B}_{2}\right)$ adalah 36,05 . Hasil perhitungan ANAVA dua jalur diperoleh $\mathrm{F}_{\text {hitung }}$ sebesar 4,588 sedangkan $\mathrm{F}_{\text {tabel }}=4,11$ pada taraf nyata $\mathrm{a}=0,05$ dan nilai siq $<0,05$ yaitu $(0,039<0,05)$. Perhitungan menyatakan bahwa $\mu B_{1}>\mu B_{2}(37,60>36,05)$ dan $F_{\text {hitung }}>F_{\text {tabel }}(4,588>4,11)$, maka $\left(\mathrm{H}_{0}\right)$ ditolak dan $\mathrm{H}_{1}$ diterima artinya terdapat perbedaan yang signifikan pada kesiapan membaca anak yang memiliki minat belajar tinggi $\left(B_{1}\right)$ dengan anak yang memiliki minat belajar rendah $\left(\mathrm{B}_{2}\right)$. Maka terdapat pengaruh X2 (minat belajar) terhadap Y (kesiapan membaca).

(3) Pengaruh interaksi (Interaction effect) yaitu melihat dan menguji pengaruh interaksi X1 X2 terhadap Y (pembelajaran ICT dan minat belajar terhadap kesiapan membaca). Hipotesis statistik dirumuskan sebagai berikut :

$\mathrm{H}_{0}:$ INT. $\mathrm{A} \times \mathrm{B}=0$

$\mathrm{H}_{1}$ : INT. $\mathrm{A} \times \mathrm{B} \neq 0$

$(\alpha=0,05, N=20)$ 
Keterangan :

$\mathrm{H}_{0} \quad$ : Tidak terdapat pengaruh interaksi Pembelajaran ICT dan minat belajar terhadap kesiapan membaca anak

$\mathrm{H}_{1} \quad$ : Terdapat pengaruh interaksi Pembelajaran ICT dan minat belajar terhadap kesiapan membaca anak

Hasil perhitungan ANAVA bahwa $F_{\text {hitung }}$ untuk faktor interaksi yaitu 74,602 lebih besar daripada $F_{\text {tabel }}$ yaitu 4,11 pada taraf nyata $\alpha=0.05$. Perhitungan menyatakan bahwa $\mathrm{F}_{\text {hitung }}>\mathrm{F}_{\text {tabel }}(74,602>4,11)$, dengan demikian $\mathrm{H}_{\mathrm{o}}$ ditolak dan $\mathrm{H}_{1}$ diterima sehingga dapat disimpulkan terdapat pengaruh interaksi pembelajaran ICT dan minat belajar terhadap kesiapan membaca anak. Bentuk grafik interaksi pembelajaran ICT dan minat belajar terhadap kesiapan membaca anak disajikan pada gambar berikut :

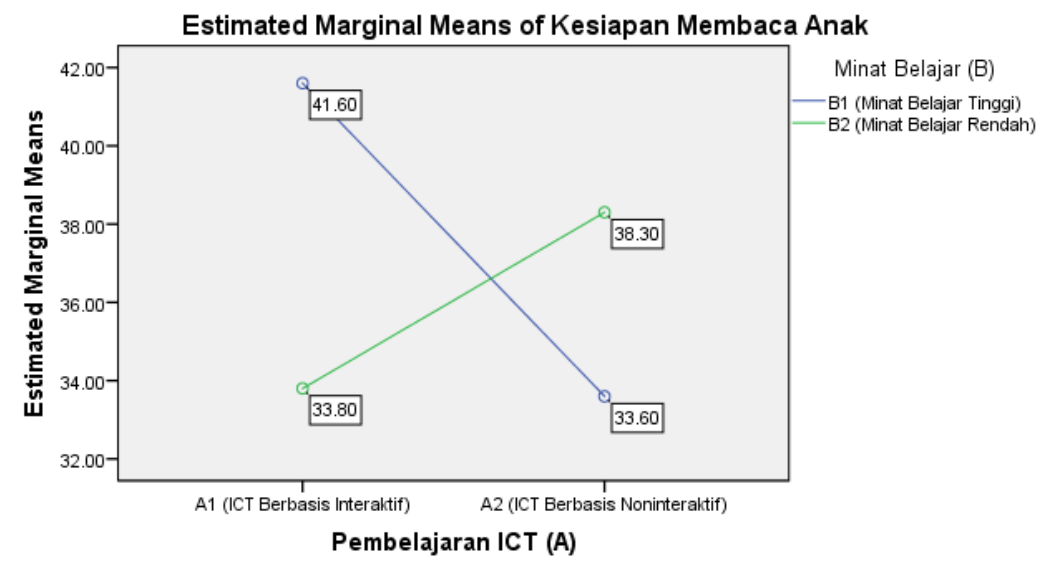

Gambar 4.1 Grafik Interaksi Pembelajaran ICT dan Minat Belajar terhadap Kesiapan Membaca Anak

Berdasarkan hasil perhitungan ANAVA dan terlihat dari gambar grafik interaksi diatas dapat disimpulkan bahwa pertama pada kelompok dengan minat belajar tinggi, kesiapan membaca lebih tinggi jika menggunakan pembelajaran ICT berbasis interaktif dibandingkan pada kelompok dengan minat belajar rendah. Kedua pada kelompok minat belajar rendah, kesiapan membaca lebih tinggi jika menggunakan pembelajaran ICT berbasis non interaktif dibandingkan pembelajaran ICT berbasis interaktif. Ketiga pada pembelajaran ICT berbasis interaktif, kesiapan membaca lebih tinggi jika anak yang memiliki minat belajar tinggi dibandingkan anak yang memiliki minat belajar rendah. Keempat pembelajaran ICT berbasis non interaktif, kesiapan membaca lebih tinggi pada anak yang memiliki minat belajar rendah dibandingkan anak yang memiliki minat belajar tinggi.

Rangkuman Hasil Perhitungan Analisis Varians (ANAVA) Dua Jalur

Tests of Between-Subjects Effects

Dependent Variable: Kesiapan Membaca Anak

\begin{tabular}{|l|r|r|r|r|r|}
\hline Source & $\begin{array}{r}\text { Type III Sum of } \\
\text { Squares }\end{array}$ & Df & Mean Square & \multicolumn{1}{|c|}{ F } & \multicolumn{1}{c|}{ Sig. } \\
\hline Corrected Model & 445.275 & 3 & 148.425 & 28.346 & .000 \\
Intercept & 54243.225 & 1 & 54243.225 & 10359.449 & .000 \\
$\mathrm{~A}$ & 30.625 & 1 & 30.625 & 5.849 & .021 \\
$\mathrm{~B}$ & 24.025 & 1 & 24.025 & 4.588 & .039 \\
$\mathrm{~A}{ }^{*} \mathrm{~B}$ & 390.625 & 1 & 390.625 & 74.602 & .000 \\
Error & 188.500 & 36 & 5.236 & & \\
Total & 54877.000 & 40 & & & \\
Corrected Total & 633.775 & 39 & & & \\
\hline
\end{tabular}

a. R Squared $=.703$ (Adjusted R Squared $=.678$ ) 


\section{Terdapat Perbedaan Kesiapan Membaca Anak yang Menggunakan Pembelajaran ICT Berbasis Interaktif dan Pembelajaran ICT Berbasis Non Interaktif}

Nilai rata-rata skor kesiapan membaca anak yang menggunakan Pembelajaran ICT Berbasis Interaktif lebih besar dari rata-rata skor Kesiapan Membaca Anak yang menggunakan Pembelajaran ICT Berbasis Non Interaktif $\left(\mu \mathrm{A}_{1}>\mu \mathrm{A}_{2}\right)$ dan nilai $\left(\mathrm{F}_{\text {hitung }}>\mathrm{F}_{\text {tabel }}\right)$, maka $\left(\mathrm{H}_{0}\right)$ ditolak dan $\mathrm{H}_{1}$ diterima artinya bahwa terdapat perbedaan yang signifikan antara rata-rata Skor Kesiapan Membaca Anak yang menggunakan Pembelajaran ICT Berbasis Interaktif $\left(\mathrm{A}_{1}\right)$ dan rata-rata skor Kesiapan Membaca Anak yang menggunakan Pembelajaran ICT Berbasis Non Interaktif $\left(\mathrm{A}_{2}\right)$.

Pembelajaran ICT berbasis interaktif menjadikan pembelajaran lebih menyenangkan melalui berbagai eksplorasi. Melalui pembelajaran ICT berbasis interaktif ini anak akan mendapatkan pengalaman bermakna untuk mendukung pembelajarannya. Pada penggunaan pembelajaran ICT berbasis interaktif harus melalui koordinasi mata dan tangan untuk kontrol, dan juga memiliki unsur seperti suara, warna, bentuk, gerak, animasi. Penggunaan kontrol dalam ICT berbasis interaktif sebagai penentu agar anak dapat memilih fitur yang diinginkan dan disesuaikan dengan game. Pada proses pembelajaran ICT berbasis interaktif yang menggunakan game, ketertarikan anak terletak pada tantangan dalam menyelesaikan game. Hal tersebut dikarenakan kegiatan yang menyenangkan dengan adanya tujuan yang menantang untuk dikejar sesuai aturan yang disetujui lebih disukai oleh anak (Nikiforidou, 2018). Lain halnya dengan pembelajaran ICT berbasis non interaktif hanya menggunakan indra pengelihatan dan pendengaran yaitu mata dan telinga namun membutuhkan aspek kognitif untuk dapat memahaminya. Maka dapat dipahami perbedaan dari pembelajaran ICT berbasis interaktif dan non interaktif terletak pada konsep dasar dalam penggunaan dan langkah-langkah penerapannya.

\section{Terdapat perbedaan Kesiapan Membaca antara Anak yang memiliki Minat Belajar Tinggi dan Anak yang memiliki Minat Belajar Rendah}

Nilai rata-rata skor kesiapan membaca anak yang memiliki minat belajar tinggi lebih besar dari rata-rata skor kesiapan membaca anak yang memiliki minat belajar rendah $\left(\mu \mathrm{B}_{1}>\right.$ $\left.\mu B_{2}\right)$ dan nilai $\left(F_{\text {hitung }}>F_{\text {tabel }}\right)$, maka $\left(\mathrm{H}_{0}\right)$ ditolak dan $\mathrm{H}_{1}$ diterima artinya bahwa terdapat perbedaan yang signifikan antara rata-rata skor kesiapan membaca anak yang memiliki minat belajar tinggi $\left(B_{1}\right)$ dan rata-rata skor kesiapan membaca anak yang memiliki minat belajar rendah $\left(\mathrm{B}_{2}\right)$.

Hal tersebut dikarenakan anak yang memiliki minat belajar tinggi lebih percaya diri, rasa ingin tahu yang tinggi dan semangat. Sedangkan anak yang memiliki minat belajar rendah cenderung belum percaya diri untuk mengeksplor, rasa ingin tahu yang rendah dan tidak menunjukkan ketertarikan sehingga ketika pembelajaran berlangsung anak tidak memperhatikan yang berdampak pada kesiapan membacanya. Selain itu anak yang memilki minat belajar tinggi lebih mampu memotivasi diri sehingga anak dengan semangat dapat mengeksplor lebih banyak dengan menggunakan pembelajaran ICT.

Hasil penelitian mengungkapkan bahwa anak yang menyukai dan sering terlibat dalam kegiatan literasi dapat mengembangkan kemampuan membaca lebih baik jika dibandingkan dengan anak yang memiliki minat belajar yang rendah. Adapun komponen penting dalam mengembangkan minat belajar didapat dari kegiatan yang menarik dan responsif. Hasil penelitian menunjukkan bahwa minat belajar dapat dimanfaatkan sebagai rencana atau strategi awal dalam mengembangkan keterampilan kesiapan sekolah, yang mana didalamnya terdapat kesiapan membaca. Anak yang memiliki minat belajar yang bagus akan menunjukkan tingkat perhatian dan upaya yang lebih baik dalam kegiatan belajar yang mengarah pada hasil belajar anak (Baroody \& Diamond, 2010). 


\section{Pengaruh interaksi Pembelajaran ICT dan Minat Belajar terhadap Kesiapan Membaca Anak.}

Hasil perhitungan ANAVA bahwa $F_{\text {hitung }}$ untuk faktor interaksi yaitu 74,602 lebih besar daripada $\mathrm{F}_{\text {tabel }}$ yaitu 4,11 pada taraf nyata $a=0.05$. dengan demikian $\mathrm{H}_{\mathrm{o}}$ ditolak dan $\mathrm{H}_{1}$ diterima dan dapat disimpulkan terdapat pengaruh interaksi antara Pembelajaran ICT dan minat belajar terhadap kesiapan membaca anak.

Pada saat ini anak tumbuh di era informasi dengan banyak perubahan terutama di bidang teknologi digital, yang telah menjadi bagian dari pegalaman sehari-hari anak. ICT bukan sesuatu yang asing bagi anak sehingga dapat digunakan untuk pembelajaran. Pada penelitian ini pembelajaran ICT dapat digunakan karena dapat disesuaikan dengan berbagai elemen yang mempengaruhi praktik pendidikan yang terus uptodate terhadap perkembangan dan bersifat komunikatif. Selain itu menggunakan berbagai unsur dalam penggunaanya yang menarik perhatian anak sehingga kegiatan belajar lebih menyenangkan.

Selanjutnya merencanakan kegiatan berdasarkan minat belajar memberikan banyak manfaat. Dengan adanya minat belajar, anak menjadi semakin semangat, fokus, aktif dan rasa ingin tahu yang semakin meningkat, sehingga berpengaruh pada kesiapan membaca anak. Sehingga dapat disimpulkan bahwa terdapat pengaruh interaksi antara pembelajaran ICT dan minat belajar anak terhadap kesiapan membaca anak.

\section{SIMPULAN}

Berdasarkan hasil analisis data, hasil pengujian hipotesis dan hasil pembahasan penelitian yang telah diperoleh maka dapat disimpulkan bahwa: (1) kesiapan membaca anak yang menggunakan pembelajaran ICT berbasis interaktif memiliki pengaruh lebih tinggi daripada yang menggunakan pembelajaran ICT berbasis non interaktif; (2) kesiapan membaca anak yang memiliki minat belajar tinggi menunjukkan pengaruh lebih tinggi daripada anak yang memiliki minat belajar rendah; (3) terdapat pengaruh interaksi antara pembelajaran ICT dan minat belajar terhadap kesiapan membaca anak.

\section{DAFTAR PUSTAKA}

Al-barakat, A. A., \& Bataineh, R. F. (2011). Preservice Teachers ' Perceptions of Instructional Practices for Developing Young Children' s Interest in Reading. Journal of Research in Childhood Education, 25(2), 37-41. https:/ / doi.org/10.1080/02568543.2011.556520

Amida, yuni ayu. (2019, February). Dampak Memaksa Anak Belajar Membaca Terlalu Dini. Haibunda.Com.

Anderson, M. J., \& Whitcomb, P. J. (2010). Design of experiments: a realistic approach. Design of experiments: a realistic approach: Routledge.

Ary, D., Jacobs, L. C., Irvine, C. K. S., \& Walker, D. (2018). Introduction to research in education. Cengage Learning.

Baroody, A. E., \& Diamond, K. E. (2010). Links Among Home Literacy Environment, Literacy Interest, and Emergent Literacy Skills in Preschoolers At Risk for Reading Difficulties. Topics in Early Childhood Special Education, 32(2), 78-87. https:/ / doi.org/10.1177/0271121410392803

Baroody, A. E., \& Oates, J. D. (2011). Child and parent characteristics, parental expectations, and child behaviours related to preschool children' s interest in literacy. Early Child Development and Care, 181, No. 3(March 2013), 37-41. https:// doi.org/10.1080/03004430903387693

Bhadra, A., Brown, J., Ke, H., Liu, C., Shin, E., Wang, X., \& Kobsa, A. (2016). ABC3D - Using An Augmented Reality Mobile Game to Enhance Literacy in Early Childhood. IEEE, 1-4. 
Cabell, S. Q., Justice, L. M., Konold, T. R., \& Mcginty, A. S. (2011). Profiles of emergent literacy skills among preschool children who are at risk for academic difficulties. Early Childhood Research Quarterly, 26, 1-14. https:// doi.org/10.1016/j.ecresq.2010.05.003

Chambers, B., Cheung, A. C. K., \& Slavin, R. E. (2016). Literacy and language outcomes of comprehensive and developmental-constructivist approaches to early childhood education: A systematic review. Educational Research Review, 18, 88-111. https://doi.org/10.1016/j.edurev.2016.03.003

Chou, P., Chang, C., \& Chen, M. (2017). Let' s Draw : Utilizing Interactive White Board to Support Kindergarten Children's Visual Art Learning Practice. Educational Technology \& Society, 20(4).

Crescenzi, L., Jewitt, C., \& Price, S. (2014). The role of touch in preschool children' s learning using iPad versus paper interaction. Australian Journal of Language and Literacy, 37(2), 86-96.

Dunst, C. J., Raab, M., \& Hamby, D. W. (2016). Interest-based everyday child language learning. Logopedia, Foniatría y Audiología, 36(4), 153-161. https://doi.org/10.1016/j.rlfa.2016.07.003

Elfil, M., \& Negida, A. (2017). Sampling methods in Clinical Research; an Educational Review. Emergency, 5.

Fridani, L., \& Agbenyega, J. (2011). SCHOOL READINESS AND TRANSITION TO PRIMARY SCHOOLS:AWHOLE SCHOOLING APPROACH. Paris International Conference on Education, Economy and Society, (20-23 July 2011), 231.

Heane. (2014, July). Tak Bisa Membaca, 8 Siswa SD Dikeluarkan Sekolah. Kaskus.

Hedges, H., Cullen, J., \& Jordan, B. (2011). Early years curriculum : funds of knowledge as a conceptual framework for children' s interests. Journal of Curriculum Studies, 43:2(November 2014), 185-205. https:// doi.org/10.1080/00220272.2010.511275

Jannah, M. (2017). Tes Kesiapan Membaca. Universitas Negeri jakarta.

Kerckaert, S., \& Vanderlinde, R. (2015). The role of ICT in early childhood education: Scale development and research on ICT use and influencing factors. European Early Childhood Education Research Journal, 23:2(May), 183-199. https:// doi.org/10.1080/1350293X.2015.1016804

Korat, O. (2014). Reading electronic books as a support for vocabulary , story comprehension and word reading in Kindergarten and first grade. Computers E Education, 55(1), 2431. https:// doi.org/10.1016/j.compedu.2009.11.014

Kucirkova, N., Sheehy, K., \& Messer, D. (2015). A Vygotskian perspective on parent- child talk during iPad story sharing. Journal of Reaseach in Reading, 38, 428-441.

Majzub, R., \& Kurnia, R. (2010). Reading readiness amongst preschool children in Pekanbaru Riau. Procedia Social and Behavioral Sciences, 9, 589-594. https://doi.org/10.1016/j.sbspro.2010.12.202

Moore-russo, D., Diletti, J., Strzelec, J., Reeb, C., Schillace, J., Martin, A., ... Prabucki, K. (2015). A Study of How Angry Birds Has Been Used in Mathematics Education. Digital Experiment Math Education, (Nctm 2000). https://doi.org/10.1007/s40751-0150008-y

Musu-gillette, L. E. (2015). Exploring the relationship between student approaches to learning and reading achievement at the school level. Journal of Early Childhood Literacy, 15. https:/ / doi.org/10.1177/1468798413512846

Neitzel, C. L., Alexander, J. M., \& Johnson, K. E. (2019). The emergence of children's interest orientations during early childhood: When predisposition meets opportunity. Learning, Culture and Social Interaction, (January), 0-1. https://doi.org/10.1016/j.lcsi.2019.01.004

Nikiforidou, Z. (2018). Digital Games in the Early Childhood Classroom: Theoretical and Practical Considerations. International Perspectives on Early Childhood Education and 
Development, 253-265. https:// doi.org/10.1007/978-981-10-6484-5

Niklas, F., Cohrssen, C., \& Tayler, C. (2016). The Sooner, the Better: Early Reading to Children. SAGE Open, 6(4). https://doi.org/10.1177/2158244016672715

Palaiologou, I. (2017). Children under five and digital technologies: implications for early years pedagogy. 1807(March), 4-24. https:// doi.org/10.1080/1350293X.2014.929876

Piasta, S. B. (2016). Current Understandings of What Works to Support the Development of Emergent Literacy in Early Childhood Classrooms. Child Development Perspectives, 10(4), 234-239. https://doi.org/10.1111/cdep.12188

Qian, M., \& Clark, K. R. (2016). Game-based Learning and 21st century skills : A review of recent research. Computers in Human Behavior, 63, 50-58. https:// doi.org/10.1016/j.chb.2016.05.023

Reinhart, M., Strickler-eppard, L., Czerniak, C. M., \& Molitor, S. C. (2012). Taking Science Home: Connecting Schools and Families Through Science Activity Packs for Young Children. School Science and Mathematics, 3-16.

Renninger, K. A., Hidi, S., Krapp, A. (2014). The role of interest in learning and development. In Psychology Press.

Renninger, K. A., \& Riley, K. R. (2012). Interest, Cognition, And The Case Of L- And Science. Cambridge: Swarthmore College Library.

Shue, P. L. (2009). Using Children' s Interests in the Learning Process. NHSA Dialog: A Research-to-Practice Journal for the Early Childhood Field, 12:1(October 2014), 66-70. https:// doi.org/10.1080/15240750802594893

Sturm, C., Galal-edeen, G. H., \& Shoukry, L. (2012). Arab Preschoolers , Interactive Media and Early Literacy Development. IEEE, 43-48.

Sudaryono. (2018). metodologi penelitian. depok: PT RajaGrafindo Persada.

Supardi. (2016). aplikasi statistika dalam penelitian. Jakarta: CHANGE PUBLICATION.

Yelland, N. (2011). Reconceptualising play and learning in the lives of young children. Australian Journal of Eaely Childhood. https:/ / doi.org/10.1177/183693911103600202 